\title{
MODEL MATERI PEMBELAJARAN POLA UNGKAPAN YANG TERDAPAT PADA LIRIK LAGU JEPANG KARYA GRUP MUSIK STEREOPONY
}

\author{
(Kajian Materi Ajar Tingkat Dasar Menengah (N4)) \\ TIARAYANTI KASIDI, Sugihartono', Aep Saeful Bachri \\ Departemen Pendidikan Bahasa Jepang, Fakultas Pendidikan Bahasa dan Sastra, Universitas \\ Pendidikan Indonesia
}

Tiarayanti91@gmail.com

\begin{abstract}
Abstrak
Pola ungkapan merupakan salah satu aspek yang sangat penting dalam bahasa Jepang. Pemahaman dan penggunaan pola ungkapan sangat dibutuhkan dalam berkomunikasi. Namun tentunya dalam bahasa Jepang ini ada beberapa pola yang sama akan tetapi penggunaannya berbeda. Pembelajar pastinya memerlukan pemahaman yang baik agar dapat menggunakan polapola tersebut sesuai dengan konteksnya. Agar pembelajar lebih mudah menguasai dan membedakan pola-pola tersebut diperlukan metode atau pun materi yang tepat. Penelitian akan berbagai metode dan media dalam pengajaran bahasa Jepang memang sudah banyak dilakukan. Namun penelitian akan materi pembelajaran itu sendiri pun diperlukan agar pengajar dapat mengemas materi pembelajaran yang memudahkan pembelajar dalam memahami pola yang diajarkan. Dalam penelitian ini penulis menggunakan 3 lagu karya Stereopony sebagai materi pembelajaran pola ungkapan tingkat dasar menengah atau setara N4. Hasil dari penelitian ini menunjukkan bahwa terdapat 15 pola ungkapan tingkat dasar menengah yang terdapat pada ke 3 lirik tersebut. Kemudian penulis mencari makna dan fungsi dari pola-pola ungkapan tersebut dari berbagai sumber, serta contoh-contoh lain dalam penggunaan pola tersebut dalam berbagai konteks. Lagu tersebut beserta fungsi dan contohnya diharapkan dapat menjadi materi pembelajaran yang dapat memudahkan pembelajar dalam memahami pola-pola ungkapan.
\end{abstract}

Kata kunci: pola ungkapan, materi pembelajaran, lirik lagu 


\title{
Expression Patterns Learning Materials Model That Found In Stereopony's Japan Song Lyrics \\ (Study Of Basic-Intermediate Level (N4) Learning Material)

\author{
TIARAYANTI KASIDI, Sugihartono', Aep Saeful Bachri \\ Departemen Pendidikan Bahasa Jepang, Fakultas Pendidikan Bahasa dan Sastra, Universitas \\ Pendidikan Indonesia
}

Tiarayanti91@gmail.com

\begin{abstract}
Abtract
The pattern of expression is one very important aspect in Japanese. Understanding and usage of the expression pattern is needed in communicating. But of course in Japanese, there are some patterns are the same but different usage. Learners certainly requires a good understanding in order to use the patterns according to the context. So that learners more easily master and distinguish the patterns required method or any appropriate material. Research about a variety of methods and media in the teaching of the Japanese language is already done. However, the research about the learning material was necessary, so that the teacher can pack the learning materials that facilitate learners in understanding the pattern taught. In this study the authors used three songs by Stereopony as expression pattern learning material of intermediate basic level or equivalent N4. Results from this study indicate that there are 15 basic-intermediate level expression patterns found on the 3 lyrics. Then the authors find meaning and function of the expression patterns from various sources, and search the examples of the patterns that use in a variety of contexts. The song and its functions and examples expected to be material that can facilitate learners in understanding the patterns of sentence.
\end{abstract}

Keyword: expression patterns, learning material, lyrics

\section{PENDAHULUAN}


Pola ungkapan merupakan aspek yang sangat penting dalam bahasa Jepang terutama dalam hal berkomunikasi. Dalam bahasa Jepang terdapat berbagai macam pola ungkapan dengan fungsi yang berbeda-beda. Namun ada pula pola yang sama tapi penggunaannya berbeda. Misalnya pola sou desu yang dapat memiliki dua fungsi yaitu yang memiliki makna "sepertinya" atau "kelihatannya", dan makna "katanya". Penggunaan kedua pola tersebut ditentukan kata kerja atau kata sifat yang ada di depannya.

Oleh karena itu agar pembelajar lebih mudah dalam mempelajari dan memahami materi pembelajaran serta agar pembelajar lebih mudah mengingat materi pembelajaran ini, maka di perlukan cara yang tepat. Untuk mempelajari pola ungkapan ini penulis memilih lagu sebagai sumber belajar, Karena sumber belajar tidak hanya merupakan buku teks saja, tetapi bisa dari mana saja. seperti yang diungkapkan Sanjaya (2008, hlm.147) bahwa selain buku teks , guru seharusnya memanfaatkan berbagai sumber belajar yang lain.

Dengan materi pembelajaran menggunakan lagu di harapkan pembelajar dapat lebih mudah untuk mengingat pola-pola ungkapan tersebut, karena ketika pembelajar mengingat lagu tersebut tidak menutup kemungkinan bahwa pembelajar akan mengingat pula fungsi dari pola yang terdapat pada lagu tersebut.

\section{METODE PENELITIAN}

Sutedi (2011, hlm.58) menjelaskan bahwa penenlitian deskriptif adalah penelitian yang dilakukan untuk menggambarkan , menjabarkan suatu fenomena yang terjadi saat ini dengan menggunakan prosedur ilmiah untuk menjawab masalah secara aktual.Oleh karena itu dalam penelitian ini penulis menggunakan metode penelitian deskriptif karena nantinya temuan dan hasil akan dijabarkan secara jelas sesuai apa yang telah ditemukan.

Penelitian ini juga termasuk kedalam penelitian kualitatif. Sugiyono (2008, hlm.1) mengemukakan bahwa metode penelitian kualitatif adalah metode penelitian yang digunakan untuk meneliti pada kondisi obyek yang alamiah, (sebagai lawannya adalah eksperimen) dimana peneliti adalah sebagai instrument kunci, teknik pengumpulan data dilakukan secara triangulasi (gabungan), analisis data bersifat induktif, dan hasil penelitian makna dari pada generalisasi.

Data yang digunakan dalam penelitian ini adalah tiga lirik lagu karya Stereopony yaitu Hitohira no Hanabira, Arigatou, dan Nakanaide, serta daftar pola ungkapan yang terdapat dalam JLPT N4. Kemudian pola yang termasuk dalam JLPT N4 yang telah ditemukan di analisis dan dicari berbagai makna dan fungsi nya. Setelah itu dicari pula contoh-contoh kalimat yang menggunakan pola tersebut dari berbagai sumber.

\section{HASIL DAN PEMBAHASAN}

a. 〜そうです

Pola ini memiliki dua fungsi yaitu:

1) Pola $\sim$ sou desu yang bermakna kelihatannya atau sepertinya. Contoh:

a) 雨が降りそうです。(Sutedi (2007, hlm.72))

Ame ga furisou desu.

'Kelihatannya akan turun hujan.'

2) Pola sou desu yang bermakna "katanya". Contoh:

b) 田中ーさんはインドネシア語を勉強しているそうです。

Tanaka-san wa Indonesia go o benkyoushiteiru sou desu.

'Katanya Tanaka-san sedang belajar bahasa Indonesia.' 
(Tjhin $(2012$, hlm.14))

b. 〜のような

Pola ini dalam bahasa Indonesia dapat diartikan sebagai kata "seperti". Contoh:

1) 起こっているようなひと。(Tjhin (2012, hlm.22))

Okotteiru youna hito.

'Orang yang seperti sedang marah.'

c. 〜のように

Pola ini memiliki beberapa makna yaitu:

1) Pola youni yang bermakna "seperti".

a) 雪のように白い。(Tjhin $(2012$, hlm.22))

Yuki no youni shiroi.

'Putih seperti salju.'

2) Pola youni yang bermakna harapan

b) 読めるように字を大きく書きます。(Tjhin (2012, hlm.23))

Yomeru youni ji o ookiku kakimasu.

'Supaya bisa dibaca, (saya) tulis besar-besar.'

3) Pola youni memiliki arti harapan pada/untuk sesuatu/seseorang.

c) 父の病気は早く治りますように。

Chichi no byouki wa hayaku naorimasu you ni.

'Semoga sakitnya Ayah lekas sembuh.'

4) Pola youni yang memiliki arti untuk menenangkan atau memerintah seseorang.

d) まだ熱いから触らないように。

Mada atsui kara sawaranai you ni.

'Karena masih panas jadi tolong jangan disentuh .'

5) Pola youni yang menjadi kata bantu untuk naru untuk memodifikasi kata kerja .

e) 日本に住んでいるから日本語が出来るようになります。 Nihon ni sunde iru kara nihongo ga dekiru you ni narimasu. 'Karena tinggal di Jepang saya menjadi bisa bahasa Jepang .'

d. 〜はず

Pengertian: hazu dapat diartikan sebagai kata "seharusnya", "mestinya", atau "pasti". Sedangkan pola hazu wa/ga nai digunakan untuk menyatakan bahwa menurut pembicara kemungkinan terjadinya sesuatu sama sekali tidak ada $(0 \%)$.

1) 彼はたなかーさんを知っているはずです。(Tjhin (2012, hlm.14))

Kare wa Tanaka-san o shitteiru hazu desu.

'Dia seharusnya kenal Tanaka-san.'

2) こんなややこしい話が子供にわかるはずがない。

Konna yayakoshii hanashi ga kodomo ni wakaru hazu ga nai.

'Tidak mungkin anak kecil bisa mengerti pembicaraan rumit seperti ini.'

(http://te.ugm.ac.id/ wibirama/yumeko/www.yumeko.web.id/2009/10/21/menggun akan-bentuk-negatif-dengan-hazu/index.html)

e. 〜ないで

Pola ini memiliki 2 fungsi yaitu sebagai berikut:

a. Pola naide yang berarti larangan

1) ここでたばこを吸わないでください。(Tjhin (2012, hlm.8)) 
Koko de tabako o suwanaide kudasai.

'Tolong jangan merokok disini.'

b. Pola naide yang berarti "tanpa"

2) 夕べ晚ご飯を食べないで寝ました。(Tjhin $(2012, \mathrm{hlm} .8))$

Yuube bangohan o tabenai de nemashita.

'Semalaman saya tidur dengan tanpa makan malam.'

f. のに

Fungsi noni: sebagai kata untuk dua kalimat yang berlawanan.

Pengertian: dapat diartikan sebagai kata "padahal", "tetapi", atau "meskipun".

1）今日は暑いのに、セーターを着ています。

Kyou wa atsui noni, seetaa wo kiteimasu.

'Padahal hari ini panas tapi saya memakai baju hangat'

(http://topbahasajepang.blogspot.co.id/2015/02/perbedaan-noni-dan-node-dalambahasa.html)

g. 〜させる

Pengertian: kata kerja yang memiliki akhiran saseru dapat diartikan sebagai "menyuruh", "membuat", "membiarkan", atau "mengizinkan".

1）母が子供に庭であそばせる。(Sutedi (2007, hlm.137))

Haha ga kodomo ni niwa de asobaseru.

'Ibu menyuruh bermain di halaman pada anak-anak.'

h. 〜てあげる

Pengertian: kata kerja yang memiliki akhiran te ageru memiliki makna "saya melakukan sesuatu untuk orang lain.

1) 私は子供におもちやを買ってあげます。(Sutedi (2007, hlm.79))

Watashi wa kodomo ni omocha o katte agemasu.

'Saya membelikan mainan untuk anak.'

i. $\quad \sim$ てくる

Fungsi: pola ini digunakan untuk menyatakan bahwa "seseorang telah melakukan sesuatu untuk saya", atau orang ke 3 telah melakukan sesuatu untuk orang ke 2.

1）父はIpod を買ってくれました。(Tjhin (2012, hlm.40))

Chichi wa Ipod o katte kuremashita.

'Ayah sudah membelikan saya ipod.'

j. 〜てごめん/すみません

Fungsi: digunakan untuk mengungkapkan permintaan maaf karena telah melakukan sesuatu.

1）遅れてすみません。(Tjhin (2012, hlm.34))

Okurete sumimasen.

'Maaf karena terlambat.'

k. 〜たら

Fungsi: di gunakan untuk pengandaian yang akan terjadi kalau ada syarat yang terpenuhi.

1) 日本に着いたら手紙をください。(Sutedi $(2007$, hlm.84))

Nihon ni tsuitara tegami o kudasai.

'Kalau sudah tiba di Jepang, kirimlah surat.

1. 〜なら 
Fungsi: digunakan dalam kalimat pengandaian, berfungsi lebih kepada pengandaian yang bersifat saran atau pemberitahuan.

1) このような仕事なら、子供でもできますよ。(Sutedi (2007, hlm.149))

Kono youna shigoto nara, kodomo demo dekimasu yo.

'Kalau pekerjaan seperti ini, anak kecil pun bisa.'

m. 〜たまま

Pengertian: Pola ini dapat diartikan sebagai "dalam keadaan..." atau menunjukkan suatu keadaan yang tetap dan tidak berubah.

1) 彼は靴を履いたまま、寝てしまいました。(Sutedi (2007, hlm.84))

Kare wa kutsu o haitamama nete shimaimashita.

'Dia tertidur dalam keadaan memakai sepatu.'

n. $\sim$ ていく

Pengertian: Pola ini dapat diartikan sebagai “pergi" atau menunjukkan suatu proses yang berlangsung mulai batas waktu tertentu.

1) 辞書を持っていきます。(Tjhin (2012, hlm.37))

Jisho o motte ikimasu.

o. 〜こと

'Saya akan pergi membawa kamus.'

Pengertian: Koto dapat diartikan sebagai "hal", atau menjadikan suatu kegiatan menjadi suatu hal atau nomina.

1) いいことも悪いことも知らせましょう。(Tjhin (2012, hlm.46))

Ii koto mo warui koto mo shirasemashou.

'Mari kita umumkan hal baik maupun hal buruk.'

\section{KESIMPULAN}

Dari pembahasan diatas, dapat kita simpulkan bahwa dari tiga lagu karya Stereopony tersebut di temukan 15 kalimat yang menggunakan pola ungkapan yang termasuk dalam pola tingkat dasar menengah atau setara JLPT N4 yaitu pola $\sim$ sou desu, no youna, no youni, $\sim$ hazu, naide, nnoni, saseru, te ageru, te kureru, te gomen/sumimasen, tara, nara, $\sim$ ta mama, $\sim$ te $i k u$, dan $\sim$ koto. . Pola-pola tersebut memiliki makna yang berbeda-beda bahkan ada pola yang memiliki fungsi lebih dari satu yaitu pola $\sim$ sou desu dan pola $\sim$ no youni.

Dengan melihat hasil penelitian ini, dapat diketahui bahwa dalam lagu-lagu Jepang terdapat pola-pola ungkapan yang dapat dipelajari, dan jika dikemas dengan penjelasan akan makna-makna dari pola ungkapan tersebut disertai contoh yang beragam, maka sebuah lagu dapat dijadikan sebagai materi pembelajaran.

\section{REFERENSI}


Sanjaya, Wina. (2008). Perencanaan dan Desain Sistem pembelajaran. Jakarta: Kencana Prenada Media Grup.

Shiang, Tjhin Thian (2012). Kiat Sukses Mudah \& Praktis Mencapai N4. Bandung: Gakushudo.

Sugiyono. (2008). Memahami Penelitian Kualitatif. Bandung: Alfabeta.

Sutedi, Dedi. (2011). Penelitian Pendidikan Bahasa jepang. Bandung: Humaniora.

Sutedi, Dedi. (2007). Nihongo no Bunpou: Tata Bahasa Jepang Tingkat Dasar. Bandung: Humaniora

http://topbahasajepang.blogspot.co.id/2015/02/perbedaan-noni-dan-node-dalam-bahasa.html

http://te.ugm.ac.id/ wibirama/yumeko/www.yumeko.web.id/2009/10/21/menggunakanbentuk-negatif-dengan-hazu/index.html 
A. はじめに

表現文型は、日本語を学んで習得しなければならない一つの余所である。学習者は、表 現文型に遵守良いしている場合、学習者は非常によく日本語でコミュニケーションでき るようになるからである。しかし、日本語の表現文型は、異なる機能を持つ非常に多様 である。学習者は、文型を理解し、覚えやすいことができるように正しい方法が必要で ある。以上のことは教材を作成することになることも出来る。この研究で筆者は日本の 歌を使用作戦のであるためな日本語の学習者は日本の歌が好きと思われた。さらに、歌 の歌詞の中で様々な表現文型が多くある。そのため、日本の歌は表現文型を勉強するた めに使用されるし、歌で日本語を学ぶとき学習者は興味があるし、そして何かを学ぶこ とが簡単に覚えられるようになる。

B. 目的 本研究の目的は、選ばれたの 3 曲ステレオポニー歌の歌詞でどんな表現文型があるこ とを見つける。そんな表現文型を知ったあと、その文型の意味または機能を見つけるし、 様々な場面他の文の例を与えるで本研究の結果は学習者が表現文型が簡単に分かる教材 になると願われた。だから、歌は聴解のメディアになるだけでなく、文法や表現文型の 教材になれることを証明することができます。

C. 研究の方法

Sutedi（2009：53）によると、研究での方法は、計画、実施、及び結論から体系的な作 業であるステップ、ある方法または手順として解釈することができることが明らかに述 ベた。

この研究で筆者は、定性的な記述法を使用していました。Sutedi（2011：58）は記述的 研究は、実際の問題を解決するために科学的な手順を使用するし、この時に発生する現 象を説明するし、例示するために行われたことを説明する。

そこで、本研究で筆者は記述的な研究方法を使用することに当たって、後で見つけたも のやこの研究の結果を明らかに説明する。

本研究は、記述的研究に含まれています。Sugiyono（2008：1）によるとこの研究で筆 者は、研究道具のキーとしてです（相手が実験であるように）、定性調査は自然である 
オブジェクトの状態を調べるために使用される研究方法であると主張しているデータ収 集技術は、三角測量（組み合わせ）を実施し、データ解析誘導性、及び一般化の研究で あるとのべられた。

本研究のサンプルでは、ステレオポニーにより 3 曲すなわちひとひらなし花びら、あり がとうと泣かないでの曲である。その歌の中であまり難しくない文型を使用するから、 学習者はその 3 曲歌を選んだのである。。それから歌の歌詞の意味は優しく意味を把握 すると思われる。

本研究ではインストゥルメントは、初級一中級あるいは日本語能力試験 N4である表現 文型のリストである。

データ収集及び処理の技術が次のようである。

1. 参考文献調査

文献の調査するために参考を読むことによってデータを収集する技術である。この場合、 筆者は、媒体の基本的なレベルに含まれる日本語能力試験、特定の文型で見出される表 現文型に関連して本を読んで、筆者はまた、学習や学習教材の準備に関連して本からデ ータを読み取り、収集する。

2. 歌詞は日本語能力試験 $\mathrm{N} 4$ に含まれる文型を用いて文章を決定、その後、中間の基本 的なレベルの表現文型に含有させることができるかを決定する。

3. この選んだ歌の歌詞である表現文型が様々な源で例として本やウェブサイトで文型の 意味を探すし分析された。そして、また、文型の他の例を見つけた。データを収集した 後、各文型の意味が締結され、筆者は学習教材の基準に合致する例を見つけられた。、

D. データ分析

「一枚の花びら」、「ありがとう」、「泣かないで」の 3 曲ステレオポニーのうち 15 の文型があり、中級の基本的なレベルの表現文型を含まれるか、または次のような同等 の N4がある。

1.〜そうです この文型は、2つの機能を有する。

a. インドネシア語の「sepertinya」あるいは「kelihatannya」と言う意味の文型 
この文型を理解するために学習を容易にするため、様々な態様 のこの文型を使用する 他の例も与えられるべきです。ここでは、この文型を使用したサンプル文である。

例: 1）雨が降りそうです。（Sutedi (2007：72))

2）あの木は倒れそうです。（Sutedi（2007：72））

3）この辞書はよさそうです。（Tjhin（2012:16））

b. インドネシア語の「katanya」と言う意味文型

例: 1）田中ーさんはインドネシア語を勉強しているそうです。（Tjhin(2012:14))

2）その車は高いそうです。（Tjhin（2012：15））

3）彼は日本語が上手だそうです。（Tjhin（2012：15））

4）天気予報によると、明日は雨だそうです。（Tjhin（2012：15）)

2.〜のような

インドネシア語でこの文型は,「seperti」という言葉と解釈することができる

別の例文：a. 幽霊を見たような顔。（Tjhin（2012：22））

b. 起こっているようなひと。（Tjhin（2012：22））

c. 子供のような大人。（Tjhin（2012:22））

d. 棒のようなもの。（Tjhin (2012:22））

e. 嘘のような話。

3.〜のように

この文型は、いくつかの意味がある

a. インドネシア語の「seperti」と言う意味文型

例: 1）先生の言うようにします。

2）お酒を飲んだように顔が赤い。

3）あなたのようにきれい。

b. インドネシア語の「supaya」と言う意味文型

例: 1）読めるように字を大きく書きます。

2）病気にならないように毎日運動しています。

3）先生は学生に勉強するように言いましました。

c. ようには何か/誰かのために希望と言う意味 
例: 1）父の病気は早く治りますように

2）U-19歳インドネシア代表は勝ちますように

d. 落ち着かせるか、人を支配することをと言う意味文型

例: 1）飲み過ぎないように気をつけてね。

2）まだ熱いから触らないように。

e. ナルを変更する単語の文型

例: 1）詳しく教えたから分かるようになきました。

2）日本に住んでいるから日本語が出来るようになります。

4.はず

はずと言うのはインドネシア語で「seharusnya」、「semestinya」、または「pasti」と言 う意味である。でも「はずが/はない」の文型は人が何かの可能性が全くない（0\%） がある起こっていることを述べるために使用される。

例: a. 彼はたなかさんを知っているはずです。

b.「たなかさんも来ますか?」「はい、そのはずです。」

c. 図書館は静かなはずです。

d. こんなややこしい話が子供にわかるはずがない。

e.そんなはずありません。もう一度確認して下さい。

5.〜ないで 次のようにこの文型は 2 つ機能がある：

a. インドネシア語の「jangan」と言う意味「ないで」である。

例: 1) ここでたばこを吸わないでください。(Tjhin(2012:8))

2) どこへも行かないでください。(Tjhin(2012:8))

3）辞書を見ないでください。(Tjhin(2012:8))

b.「なし」と言う意味「〜ないで」である。

例: 1）朝ご飯を食べないで学校へいきました。（Sutedi（2007：80））

2）夕べ晚ご飯を食べないで寝ましました。

6.のに

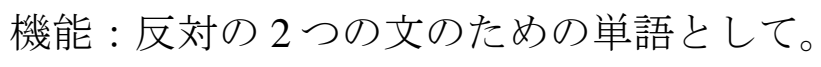


定義：それはインドネシア語で「padahal」「tetapi」、「meskipun」、「untuk」と解 釈することができる、

例 : a. 今日は暑いのに、セーターを着ています。

b. 昨日は休みだったのに、仕事をしましました。

c. 来週テストがあるのに、弟は遊んでいます。

d. ダイエットをしたのに、太りましました。

(http://topbahasajepang.blogspot.co.id/2015/02/perbedaan-noni-dan-node-dalambahasa.html)

7. 〜させる

定義：〜させるは、「作成」、「送信」または「許可」と解釈することができます。

例: a. 兄は弟に本を読ませましました。(Sutedi (2007:134))

b． 先生が生徒達を座らせます。S(utedi (2007:137))

c. 先生が生徒達に座らせます。(Sutedi (2007:137))

8.〜てあげる

この文型は、フレーズにあります。

定義：「〜てあげる」持っている動詞は「私は他の誰かのために何かをやっている」 という意味。

例: a. 私は子供におもちゃを買ってあげます。（Sutedi（2007：79）

b． 私は弟に荷物を運んであげます（Sutedi（2007：95））。

c. 私はさとうーさんをホテルまで案内してあげます。

d．私は妹を病院へ連れてあげました。

e. 私は山田さんの車を洗ってあげます。

9. 〜てくれる

機能 : この文型は、「誰かが私に何かを行っている」、または 3 人が 2 人のために何か を行っていることを宣言するために使用される。

例: a. iPodの父はを買ってくれました。（Tjhin（2012：40））

b.お金を貸してくれませんか。（Tjhin（2012：40））

c. 田中ーさんは夕飯を作ってくださいました。（Tjhin（2012：40）） 

d．あの人は道を教えてくださいました。（Tjhin（2012：40））
e. たなかさんにダーさんに漢字を読んでくれました。
$\lceil 79\rfloor$

10.〜てごめん/すみません

機能 : 何かをしたことで謝罪を表現するために使用される。

例:a．遅れてすみません。（Tjhin（2012：34））

b. 声が大きくてすみません。（Tjhin（2012：34））

c. 話が複雑ですみません。（Tjhin（2012：34））

d. 污い言葉を使ってすみませんでした。

11. 〜たら

機能 : 何の条件が満たされていない場合に発生する前提に使用。

例: a. 日本に着いたら手紙をください。（Sutedi（2007：84））

b. あの先生に聞いてみたらどうですか。（Sutedi（2007：84））

c. 日本へ行ったら、手紙をください。（Sutedi（2007：148））

d. 試験が終わったら遊びに行きましょう。（Sutedi（2007：148））

12.なら

機能 : 文モダリティで使用されるが、アドバイスや通知である仮定により機能する。

例: a. このような仕事なら、子供でもできますよ。(Sutedi (2007：149))

b. 車を買うなら、日本の車が安いですよ。(Sutedi (2007：149))

c. そんなに頭が痛いなら、この薬がいいですよ。(Sutedi (2007：149))

d. 私があなたならば、そんなことはしない。(Sutedi (2007：149))

13. 〜たまま

機能:インドネシア語の「dalam keadaan」と言う意味である。

例: a. 彼は靴を履いたまま、寝てしまいました。(Sutedi (2007:84))

b. 電気をつけたまま寝てしまいました。(Tjhin (2012:45))

c. ドアを閉めないまま出かけてしまいました。(Tjhin (2012:45))

14. 〜ていく

機能:ものがこちらに向かって移動している/ちらから向こうへ移動している/特別な できごとの日時が近づいている。 
JAPANEDU, Vol. 1, No. 1, April 2016

例: a. 辞書を持っていきます。(Tjhin (2012:37))

b. 学校までバスに乗っていきます。(Tjhin (2012:37))

c. この国は強くなっていくはずです。 $(T j h i n ~(2012: 37))$

15. 〜こと

機能:文の名詞化

例: a. いいことも悪いことも知らせましょう。(Tjhin (2012:46))

b. 大事なことを教えてもらいました。(Tjhin (2012:46))

c. 田中先生のことを思い出しました。(Tjhin (2012:46))

E. 終わりに

本研究には 3 曲の中で表現文系が 15 つる。本研究の結果を見るで教師が正しい方法 で教材を作成したら日本の歌は開発教材になれるのでこの方法で学習者は教材が分かり やすいと願われる。次の筆者はこの歌で教材として教えるに関する研究をするのが実施 する。

F. 参考文献

Shiang, Tjhin Thian (2012). Kiat Sukses Mudah \& Praktis Mencapai N4. Bandung: Gakushudo. Sugiyono. (2008). Memahami Penelitian Kualitatif. Bandung: Alfabeta.

Sutedi, Dedi. (2011). Penelitian Pendidikan Bahasa jepang. Bandung: Humaniora.

Sutedi, Dedi. (2007). Nihongo no Bunpou: Tata Bahasa Jepang Tingkat Dasar. Bandung: Humaniora

(http://topbahasajepang.blogspot.co.id/2015/02/perbedaan-noni-dan-node-dalam-bahasa.html) 